\title{
(6) Prospects and Reasonable Treatment of Coronary Atherosclerotic Heart Disease in Japan
}

\author{
Hiroshi Yamaguchi, MD
}

Depariment of Cardiology and Internal Medicine Toranomon Hospital, Minato-ku, Tokyo

Although the incidence of atherosclerotic coronary artery disease in Japan is still fairly low (one fifth or eights) as compared with that in the U.S.A. or Western countries, it has surprisingly increased in the last few decades, especially in younger generation $^{1)}$ and saphenous vein bypass graft surgery (SVBG) has been performed in increasing frequency as a valid treatment for unstable angina ${ }^{2)}$. The present study was attempted to clarify the etiological factors for increasing coronary artery disease in Japan and whether the pathoanatomical type of Japanese coronary artery disease is essentially similar to that of American or Western people, or not. Moreover, by evaluating survival prognosis in medically treated patients and angiographic progression of their coronary artery disease, an attemp was also made to assess whether SVBG should be performed in such a frequency as to be a boom in the modern medicine, or fundamental medical treatment is well acceptable for Japanese patients.

\section{MATERIAL AND METHODS}

From September, 1973 through Feburary, 1978, 998 patients underwent selective cine coronary arteriography at Toranomon Hospital for the evaluation of ischemic heart disease or cardiomyopathy. Of these, consecutive 369 patients with 70 to $100 \%$ fixed organic stenosis in major coronary arteries and the first consecutive 100 patients with normal coronary arteriograms (control group) are the subject of this report. In all patients, clinical data and atherosclerotic risk factors are recorded and analyzed. Selective cine coronary arteriography and ventriculography were performed using Sones technique. All studies were recorded on $35 \mathrm{~mm}$ film at a rate of 32 frames/sec. The angiographic films were interpreted successively by an experienced cardiologist. Of 369 patients, 46 underwent SVBG because of their younger ages and coronary arteay disease being ideally graftable, but not because of the severity of their disease or intractable angina. The remaining 323 patients were followed up for maximum 4 years on the medical treatment which consisted of low animal fat diet, reduction of body weight, stop of smoking and medication including anticoagulant (Warfarin), propranolol, clofibrate, isosorbide dinitrate and so forth. Therefore, patients with more severe coronary artery disease or poorer left ventricular function and also elder inoperable patients were included in the medically treated group. Among the 323 medically treated patients, 21 were re-studied by cine angiography to evaluate progression or regression of coronary artery disease at interval of 5 to 68 months (average; 33.5 months). All coronary arteriograms were of good technical quality to allow adequate comparison between studies.

\section{RESULTS}

\section{Type of Japanese coronary artery disease} For comparison in disease type between Japanese and American coronary artery disease, all patients were classified into two types, diffuse multiple (D) and localized (L), according to the following criteria: (D) having at least two stenosis of greater than $70 \%$ in more than two major coronary arteries including the middle segment; and $(\mathrm{L})$ having stenosis of greater than $70 \%$ in the fewer number of major coronary 
arteries.

Of the first consecutive 226 patients with coronary artery disease of greater than $70 \%$ stenosis, 141 (62.4\%) were localized type and $85(37.4 \%)$ diffuse, multiple. For comparison, 500 American patients with coronary artery disease of greater than $70 \%$ stenosis were reviewed and classified in the same way according to the same criteria as used on Japanese patients. These were the consecutive 500 patients who underwent coronary cine angiography at Cleveland Glinic, Ohio. Two handred eighty-one patients were localized (56.3\%) and 219 diffuse, multiple (43.7\%). The mean age of 226 Japanese patients was 53.6 years, and 53. 4 years was that of American (The difference is statistically not significant.). Analysis of 123 Japanese patients with prior myocardial infarction revealed 82 (66\%) with localized type whereas $40 \%$ with localized type in American patients. Thus, as far as disease type is concerned, there is no significant difference in distribution between Japanese and American patients.

\section{Analysis of coronary risk factors}

The serum cholesterol level was greater

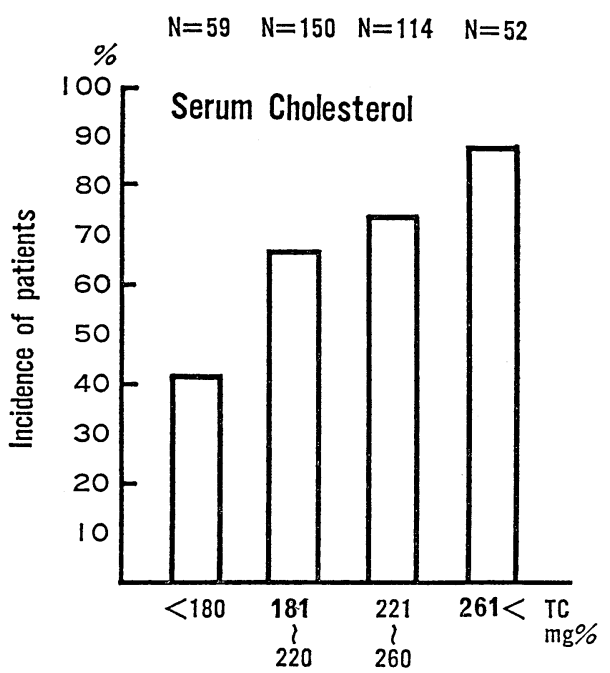

in the total coronary artery disease group compared with the control group $(230 \mathrm{mg} / \mathrm{dl}$ $\pm 3 \mathrm{vs} 204 \pm 2, \mathrm{P}<0.01)$. The similar difference was present in the mean serum triglyceride $142 \mathrm{mg} / \mathrm{dl} \pm 5$ vs $108 \pm 4, \quad \mathrm{P}<0.01)$. The percentage of patients with coronary artery disease rose progressively as the level of both cholesterol and triglyceride increased even from the low normal level (lower than $180 \mathrm{mg} / \mathrm{dl}$ of cholesterol and $80 \mathrm{mg} / \mathrm{dl}$ of triglyceride; Fig. 1). Moreover the mean value of cholesterol in diffuse multiple disease subgroup was significantly higher $(240 \mathrm{mg} / \mathrm{dl} \pm 3$ vs $215 \pm 2, \mathrm{P}<0.01)$ than that in localized group. However, triglyceride had no relation to disease type. These findings are entirely identical with those seen in American patients reported by Cohn et $\mathrm{al}^{3)}$.

3. Natural history of coronary atherosclerotic heart disease in Japan; comparison between medical and surgical treatment

i) Mortality in surgically treated patients.

Forty-six patients had revascularization surgery (SVBG) in whole study population. There were 8 deaths (17.3\%) from surgery. One patient was attributed to postopera-

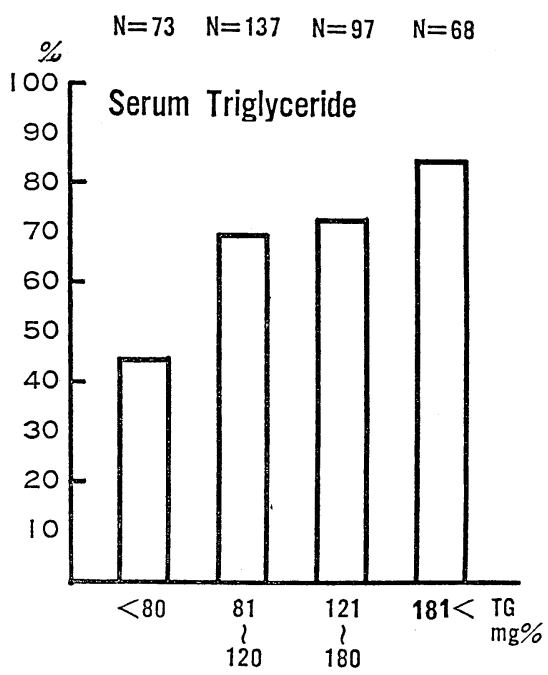

Fig. 1. Relationship between percent incidence of ASHD and serum lipid levels. The percentage of patients with coronary artery disease rises progressively as the levels of both total cholesterol (left) and triglyceride (right) increase even within normal rangest 
Table 1. Mortality Statistics of ASHD Medically Treated Patients

\begin{tabular}{cccc}
\hline & No. of pts. & $\begin{array}{l}\text { No. of } \\
\text { pts. died }\end{array}$ & Percent death \\
\hline 1VD & 128 & 2 & $1.6 \%$ \\
MI* (-) & 53 & $1(1)^{* * *}$ & 1.9 \\
MI (+) & 75 & 1 & 1.3 \\
2VD & 95 & 3 & $3.2 \%$ \\
MI (-) & 45 & 0 & 0 \\
MI (+) & 50 & 3 & 6.0 \\
3VD & 100 & 6 & $6.0 \%$ \\
MI (-) & 41 & $2(1)^{* *}$ & 4.9 \\
MI (+) & 59 & $4(1)^{* *}$ & 6.8 \\
\hline Total & 323 & $11(3)^{* *}$ & $3.4 \%$ \\
\hline LMT & 17 & 3 & $17.6 \%$ \\
\hline * MI: myocardial infarction & $* *(1)$ non-cardiac death
\end{tabular}

Table 2. Mortality Statistics of ASHD Medically Treated Patients

\begin{tabular}{|c|c|c|c|c|c|c|}
\hline & \multicolumn{3}{|c|}{ 2-4 Years Follow-up } & \multicolumn{3}{|c|}{ 3-4 Years Follow-up } \\
\hline & $\begin{array}{l}\text { Total No. } \\
\text { of pts. }\end{array}$ & $\begin{array}{l}\text { No. of } \\
\text { pts. died }\end{array}$ & $\begin{array}{l}\text { Percent } \\
\text { death }\end{array}$ & $\begin{array}{l}\text { Total No } \\
\text { of pts. }\end{array}$ & $\begin{array}{l}\text { No. of } \\
\text { pts. died }\end{array}$ & $\begin{array}{l}\text { Percent } \\
\text { death }\end{array}$ \\
\hline IVD & 53 & 2 & $3.7 \%$ & 32 & 2 & $6.3 \%$ \\
\hline $\mathrm{MI}^{*}(-)$ & 24 & 1 & 4.1 & 16 & 1 & 6.3 \\
\hline $\mathrm{MI}(+)$ & 29 & 1 & 3.4 & 16 & 1 & 6.3 \\
\hline $2 \mathrm{VD}$ & 43 & 2 & $4.3 \%$ & 29 & 2 & $6.9 \%$ \\
\hline $\mathrm{MI}(-)$ & 20 & 0 & 0 & 12 & 0 & 0 \\
\hline $\mathrm{MI}(+)$ & 23 & 2 & 8.7 & 17 & 2 & 11.8 \\
\hline $3 \mathrm{VD}$ & 45 & 5 & $11.1 \%$ & 26 & 3 & $11.5 \%$ \\
\hline MI (-) & 17 & 1 & 5.9 & 7 & 1 & 14.3 \\
\hline MI $(+)$ & 28 & 4 & 14.3 & 19 & 2 & 10.5 \\
\hline Total & 141 & 9 & $6.4 \%$ & 87 & 7 & $8.0 \%$ \\
\hline LMT*** & 7 & 2 & $28.6 \%$ & 4 & 1 & $25.0 \%$ \\
\hline
\end{tabular}

*MI: myocardial infarction, ${ }^{* *}$ LMT: left main trunk lesion

tive serum hepatitis. None of the remaining 36 patients died during the follow-up period.

ii) Mortality in medically treated patients.

a) Overall mortality in all medically treated patients. There were 11 deaths (3.4\%) out of total 323 medically treated patients during the entire observation period. Additional 3 deaths were noncardiac in etilogy. Table 1 shows the number of patients and deaths in one, two and three vessel disease (1VD, 2VD and $3 \mathrm{VD})$, respectively. There were 3 deaths of 20 patients with left main trunk lesion who were included in either two or three vessel disease. None died from cine angiography.

b) 2 to 4 year mortality.

Table 2 shows mortalities of medically treated patients during the follow-up period of 2 to 4 years (left column) and 3 to 4 years (right column). Overall mortality rate of each group was $6.4 \%(9 / 141)$ and $8.0 \%(7 / 87)$, respectively. In the former group, patients with $1 \mathrm{VD}, 2 \mathrm{VD}$ and $3 \mathrm{VD}$ had $3.7 \%(2 / 53), 4.3 \%(2 / 43)$ and $11.1(5 / 45)$ mortality rates, respectively. In the group of 87 patients followed up for 3 to 4 years, 1VD, 2VD and 3VD had 6.3\% (2/32), $6.9 \%(2 / 29)$,and $11.5 \%(3 / 26)$ mortality rates, respectively.

c) Mortality of patients with anticoagulant therapy for unstable angina.

Fifty-two patients received Warfarin treatment for their unstable angina with

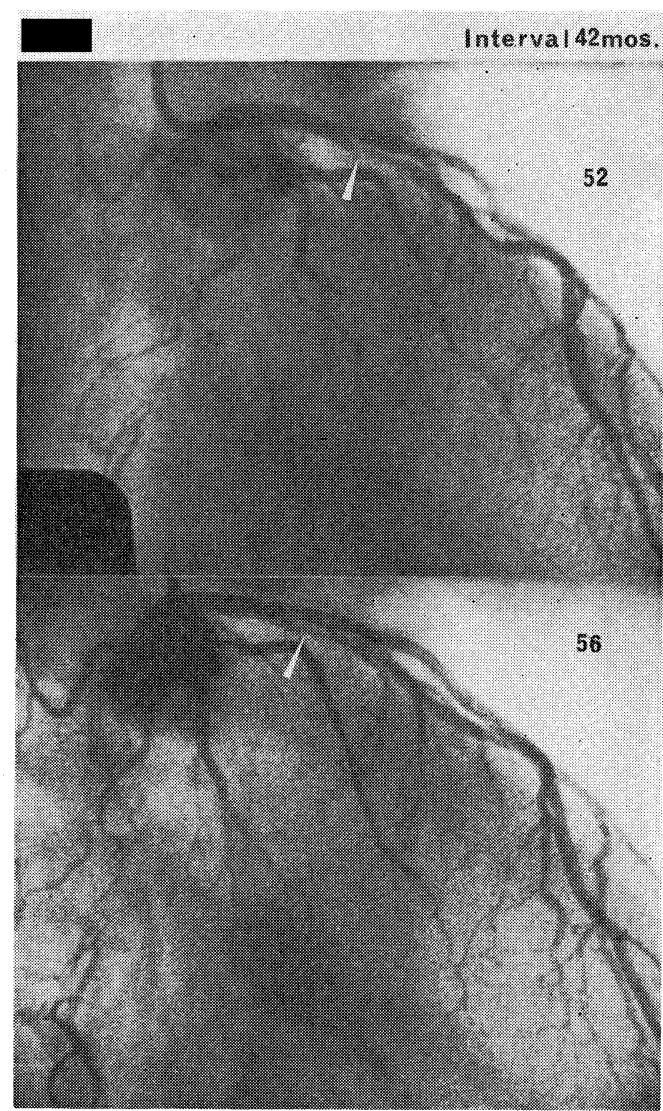

Fig. 2. Regression of obstructive coronary artery disease demonstrated in a medically treated 56 years old male patient. More than 95\% obstruction seen in the proximal LAD (arrow) at the time of the first study (upper panel) became about $70 \%$ rat the second study performed after 4 years (lower panel). The patient continued Warfarin therapy. 
jeopardized severs occlusive coronary artery disease (greater than 90\% stenosis). There were four deaths in 52 patients (7.8\%) during the observation period of 1 to 4 years. All of the four deaths were found only in 3VD group (4/38) and none in IVD $(0 / 7)$ or $2 \mathrm{VD}(0 / 8)$. Three of the four deaths were found in patients with prior myocardial infarction and $3 \mathrm{VD}$, and the remaining one in patients with severs $3 \mathrm{VD}$ involving left main trunk although having good myocardial function.

Thus, anticoagulant therapy yielded an excellent result in survival prognosis of patients with unstable angina.

\section{Progression or regression of coronary artery disease in medically treated pa- tients}

Twelve (76\%) of 21 patients re-studied by selective cine coronary arteriography demonstrated regression $(4 / 21,19 \%)$ or no progression $(12 / 21,57 \%)$ in their occlusive coronary artery disease (Fig. 2). Four patients revealed progression within two years. One patient who developed myocardial infarction was not on good diet or did not stop smoking to avoid coronary risk factors.

\section{COMMENTS AND CONCLUSION}

Judging from the results of the present study, in Japanese modico-social situation ${ }^{2)}$, fundamental medical treatment is much more beneficial than surgical treatment for the improvement of survival prognosis in patients with severe coronary artery disease. Mortality rate found in medically treated Japanese patients seems to be much better than that of patients in America or Western countries ${ }^{4,5,6,7)}$. From the point of view of therapeutic goal, improvement of quality of life is essentially important. In this point our medical treatment is by no means inadequate remedy, but actually patients even with anticoagulant therapy can lead themselves productive lives. As a supportive way of thinking for propriety of medical treatment, one can postulate that if medical treatment including anticoa- gulation can stop or effectively slow down the progression of occlusive coronary artery disease and also protect patients with severe coronary artery disease from developing myocardial infarction for more than certain period of time, collateral circulation will gradually develop in the region of ischemic myocardium to sufficiently compensate the inadequate antegrade flow through the obstructed coronary artery. In this situation, surgical intervention is not necessary any more. If such situation can not be guaranteed from angiographic findings as well as clinical data, effective but palliative SVBG should be considered. The operative indication, however, should be limited only in patients of younger age than 60 years with left main trunk stenosis or more than $70 \%$ narrowing in proximal anterior descending artery, or jeopardized collaterals compensating obstructed major coronary artery. Patients with these lesions have potentially high risk in survival prognosis and more or less limitation in their activities $^{8,9,10)}$.

ACKNOWLEDGEMENTS: The author gratefully acknowledge the assistance of Miss Sumiko Hashimoto in lipid chemistry and statistical analysis.

This work was supported in part by Okinaka Memorial Institute for Medical Research.

\section{REFERENCES}

1) Sawai K, Nikaido $\mathrm{T}$ and Ito $\mathrm{Y}$ : Epidermology of myocardial infarction. Clinic Allround $27: 209,1978$.

2) Asada S: Coronary surgery in Japan-present states and future. Cardioangiology 1 : 419, 1978.

3) Cohn PF, Gabbay SI and Wegliki WB: Serum lipid levels in angiographically defined coronary artery disease. Ann Intern Med 84 : 241, 1976.

4) Bruschke AVG, Proudfit WL and Sones FM, Jr: Progress study of 500 consecutive nonsurgical cases of coronary disease followed 5-9 years. I. Arteriographic correlations. Girculation 47: 1147, 1973.

5) Arinow WS and Stammer EA: Two year follow-up of angina pectoris. Ann Intern

Jap J Med Vol 17, No 4 (Oct 1978) 
Med 82: 208, 1975.

6) Nelson GR, Gohn PF and Gorlin R: Prognosis in medically-treated coronary artery disease. Influence of ejection fraction compared to the other parameters. Circulation 52 : 408, 1975.

7) Murphy ML, Hultgren $\mathrm{HN}$ and Detre, et al: Treatment of chronic stable angina. A preliminary report of survival data of the randomized Veterans Administration Cooperative Study. New Engl J med 297: 621, 1977.

8) Oberman A, Harrell RR, Russell QO, Jr, et ai: Surgical versus medical treatment of the left main coronary artery. The Lancet 2: 591, 1076.

9) Koukoukos NT, Oberman A, Russell RO et ai : Surgical versus medical treatment of occlusive disease confined to the anterior descending coronary artery. Am J Cardiol 35 : 836, 1975.

10) Nakanishi S, Nagasaki F, Matsumoto S, et ai: Clinical features of patients with obstruction in left coronary main trunkreport of 8 cases. J Japanese College of Angiology 17: 495, 1977.

\title{
(7) Indication and Long-Term Results of Artificial Cardiac Pacemaker
}

\author{
Kunitake Hashiba, MD
}

The Third Department of Internal Medicine, Nagasaki University School of Medicine

Implantation of artificial cardiac pacemaker has been established as the most effective treatment for bradyarrhythmias, including A-V block and sick sinus syndrome. The number of patients who underwent pacemaker implantation in Japan is presumed to be beyond 5, 000 until 1976.

\section{INDICATION OF PACEMAKER IMPLANTATION IN A-V BLOCK}

A-V block should be treated with pacemaker implantation when complicated by attack of cerebral ischemia, varying from classical Adams-Stokes attack to dizziness as an equivalent of the former, in the following situations; (1) complete A-V block, (2) Mobitz type II second degree A-V block, (3) association of complete RBBB and left anterior or posterior fascicular block, even with $1: 1 \mathrm{~A}-\mathrm{V}$ conduction in the electrocardiograms recorded in the interim period, and (4) bilateral bundle branch block.

Symptoms of heart failure and/or disabling easy fatigue would also be indication for pacemaker implantation in patients with complete heart block. Use of pacemaker for stable complete A-V block without recent complication of AdamsStokes attack or other symptoms has been controversial.

His bundle electrogram and atrial pacing technique would be useful procedures in determining indication of pacemaker implantation in patients with $\mathrm{A}-\mathrm{V}$ block of various degrees. In our series of 30 paced patients with complete or advanced A-V block 7 showed A-H block, 5 H-H' block, and $18 \mathrm{H}-\mathrm{V}$ block in the His bundle electrograms, respectively. The other 2 patients showed 2: $1 \mathrm{H}-\mathrm{V}$ block.

\section{LONG-TERM RESULTS OF PACEMAKER IMPLANTATION IN A-V BLOCK}

The Committee on Artificial Cardiac Pacemaker in Japan performed a survey of long-term follow-up of patients with chronic complete or advanced A-V block in 1972. The cumulative survival rate over 5 years in 363 unpaced and in 276 paced patients with complete A-V block was shown as 